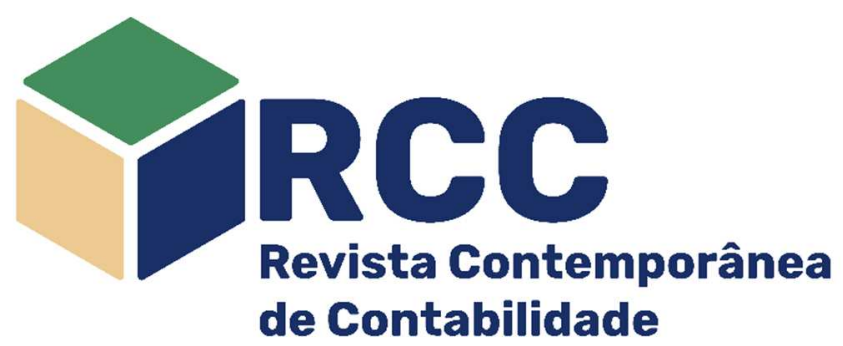

\title{
Características individuais relevantes ao conselheiro de administração independente
}

\author{
Individual characteristics relevant to the independent board member
}

\section{Características individuales relevantes al consejero de administración independiente}

\author{
Ciro Antonio Fernandes \\ Doutor em Administração (USCS) \\ Professor do Centro Universitário (FMU), \\ São Caetano do Sul/SP, Brasil \\ ciro_af2@hotmail.com \\ https://orcid.org/0000-0002-3346-8780
}

\author{
Eduardo de Camargo Oliva* \\ Pós-Doutor e Doutor em Administração (USP) \\ Diretor e Professor do Programa de Pós-Graduação- \\ Mestrado e Doutorado PPGA (USCS), São Caetano do Sul/SP, Brasil \\ eduardo.oliva@prof.uscs.edu.br \\ https://orcid.org/0000-0002-7454-3759 (1) \\ Edson Keyso de Miranda Kubo \\ Doutor em Administração (FGV/EAESP), São Caetano do \\ Sul/SP, Brasil \\ edson.kubo@prof.uscs.edu.br \\ https://orcid.org/0000-0001-9017-2487 (1)
}

Endereço do contato principal para correspondência* Rua Conceição, 321 - Santo Antônio, CEP: 09530-060, São Caetano do Sul/SP, Brasil

\section{Resumo}

Apesar da relevância do papel de conselheiro de administração independente, são escassas as pesquisas acerca de suas características individuais para suas atividades no contexto brasileiro. Por meio de uma pesquisa de abordagem qualitativa, orientada pela história oral, foram entrevistados 30 membros, sendo quinze presidentes e quinze conselheiros de administração independente, pertencentes às empresas listadas no Novo Mercado da B3, localizadas nas regiões sul e sudeste do Brasil, entre os meses de julho a novembro de 2017. O roteiro de entrevistas contemplou aspectos nominais, cognitivos e comportamentais e os achados foram tratados por meio da análise de conteúdo. Os resultados indicaram que as características de atuação independente, credibilidade e trajetória e o acúmulo de experiências são essenciais no processo de escolha do conselheiro dentre várias outras e que todas são complementares entre si. Esta pesquisa contribuiu teoricamente para mapear as características que rompem com o personalismo, nas indicações de conselheiros independentes.

Palavras-chave: Conselheiro de Administração independente; Conselho de Administração; Governança Corporativa

\begin{abstract}
Despite the relevance of the role of the independent board member, research on their individual characteristics for their activities in the Brazilian context is scarce. Through a qualitative research, guided by oral history, 30 members were interviewed, including fifteen presidents and fifteen independent directors, belonging to companies listed on B3's New Market, located in the south and southeast regions of Brazil, among the months from July to November 2017. The interview guide included nominal, cognitive and behavioral aspects and the results found through content analysis. The results indicate that the characteristics of independent performance, credibility and trajectory and accumulation of experiences are essential in the process of choosing a board member among several others and that they are all complementary to each other. This research theoretically contributed to map the characteristics that can break with personalism, in the nominations of independent board members.
\end{abstract}

Keywords: Independent Board Member; Board; Corporate Governance 


\section{Resumen}

A pesar de la relevancia de consejero de administración independiente, la investigación sobre sus características individuales para sus actividades en el contexto brasileño es escasa. A través de una investigación cualitativa por la historia oral, se entrevistó a 30 miembros, incluidos quince presidentes y quince consejeros, pertenecientes a empresas que figuran en el Novo Mercado de B3 en las regiones sur y sureste de Brasil, entre los meses de julio a noviembre de 2017. El guion de la entrevista incluía aspectos nominales, cognitivos y de comportamiento, y los resultados se trataron mediante análisis de contenido. Los resultados indicaron que las características de desempeño independiente, credibilidad y trayectoria y la acumulación de experiencias son esenciales en el proceso de elegir un consejero entre varios otros y que todos son complementarios entre sí. Esta investigación contribuyó teóricamente a mapear las características que rompen con el personalismo, en las indicaciones de los consejeros independientes.

Palabras clave: Consejero de Administración; Consejo Administrativo; Gobierno Corporativo

\section{Introdução}

Os conselheiros de administração são agentes estratégicos que atuam de forma sistemática e contínua no monitoramento da gestão, na orientação estratégica e na implementação e monitoramento dos objetivos corporativos (STEINBERG, 2003; OECD, 2008). Quando os membros do board são escolhidos a partir de características individuais bem definidas e alinhadas com objetivos estratégicos da organização, criam valor ao conselho de administração e à empresa (KACZMAREK; KIMINO; PYE, 2012).

Outro aspecto relevante a ser apontado é a importância da harmonia entre as características individuais dos conselheiros de administração com os princípios de governança corporativa. Essa congruência pode elevar o grau de confiança dos investidores criando um ambiente propício à atração de recursos externos, permitindo a sobrevivência da empresa e o bom funcionamento da economia e do mercado (CLAESSENS, 2003; OECD, 2004).

Diversos estudos apresentados como os de Charan (2007); Coulson-Thomas (2009); Oliveira (2011); Camilo; Marcon, Bandeira-de-Mello (2012); Dunn (2012); Purdy e Lawless (2012); Darmadi (2013); Mathisen; Ogaard, Marnburg (2013); Freire et al. (2015); Wagner (2015); Pugliese; Nicholson e Bezemer (2015); Silva e Magem (2015) corroboram o pressuposto de que as características individuais, quando apropriadas ao exercício da atividade de Conselheiro de Administração, aumentam a capacidade do conselheiro de colaborar com o desempenho do conselho e da organização.

Nesse sentido, a escolha de um candidato sem base meritocrática, sem contemplar reais competências para exercer a atividade de conselheiro de administração, pode influenciar negativamente o desempenho do Conselho de Administração e da organização (PURDY; LAWLESS, 2012).

A prática atual no Brasil, assim como em outros países, é de se escolher o conselheiro de administração por outros motivos, que não sejam suas competências. Vê-se como prática para a escolha do conselheiro a troca de favores ou pelo seu trânsito político, o que pode, em alguma medida, fazer com que a escolha fique limitada à indicação pessoal ou de grupos que o candidato representa (OLIVA; ODONE; ALBUQUERQUE, 2008).

Ao se repensar os critérios de escolha do conselheiro de administração, propõe-se um novo mapeamento, no qual os conselheiros são escolhidos por possuírem características individuais capazes de contribuir efetivamente com o conselho.

Dessa maneira, o objetivo dessa pesquisa é conhecer as características individuais necessárias à atividade de conselheiro de administração independente. Espera-se, a partir dos resultados obtidos, contribuir para a construção de um perfil que possa ser utilizado pelos conselhos como um balizador para as características requeridas ao conselheiro.

Havendo um conjunto de características pré-definidas, também é possível orientar a construção das grades curriculares dos cursos que tenham por objetivo a formação ou o aperfeiçoamento dos conselheiros de administração. A indicação e escolha de conselheiros de administração, baseada em suas competências. pode favorecer a busca de candidatos experimentados pelo mercado e com expertise em suas funções, dando mais efetividade e assertividade nas tomadas de decisão pelo conselho.

Este artigo está dividido em seis partes principais. Logo após essa introdução, seguem a revisão da literatura, abordando as teorias de alto escalão e a diversidade de perfis dos conselheiros de administração. Após isso, continua-se com a metodologia e a apresentação e discussão de resultados, que foi dividida em subseções. Conclui-se então com as considerações finais, seguidas das referências.

\section{Teoria do Alto Escalão}

A teoria do alto escalão surge inicialmente da pesquisa de Hambrick e Mason (1984), que afirmam que a equipe executiva é um recurso estratégico e que o desempenho organizacional resulta das características e escolha desses executivos. Nesse sentido, dentre os vários estudos (PURDY, LAWLESS, 2012; BHAT; CHEN; JEBRAN; MEMON, 2019; AI-MATARI, 2019; KACANSKI, 2019) que compõem a teoria do alto escalão foram encontrados aqueles que proporcionaram uma combinação de competências 
profissionais dos diretores do alto escalão, posição análoga aos membros do board, que vão ao encontro do objetivo desse estudo.

A partir da teoria do alto escalão e de outras pesquisas que fazem parte desta revisão da literatura, procura-se conhecer quais características individuais possuem maior alinhamento e relevância à atividade de conselheiro de administração.

Inicialmente, a teoria do alto escalão apresenta a experiência vivenciada ao longo do exercício da atividade de diretor do alto escalão, de acordo com os estudos de Hambrick e Mason (1984), Finkelstein e Hambrick (1990), Gary, Wood e Pillinger (2012), Clark e Maggitti (2012), Bhat, Chen, Jebran e Memon (2019), Al-Matari (2019) e Kacanski (2019) como uma condição capaz de criar no indivíduo, características diferenciadas no momento da tomada de decisão.

De maneira mais objetiva, pode-se dizer que as experiências vivenciadas são únicas para cada indivíduo e, portanto, cada qual constrói um significado particular a partir das lições aprendidas. Como no caso dos diretores que se tornam mais cautelosos nas tomadas de decisões, após exercerem seu mandato por um longo período (HAMBRICK; MASON, 1984). Outros passam a ser mais persistentes na implementação das estratégias e na busca por um desempenho que esteja mais alinhado às médias da indústria, conforme propõem Finkelstein e Hambrick (1990). Segundo os autores a persistência também decorre do tempo de permanência do diretor no cargo. Das experiências vivenciadas também surge a capacidade de se tomar uma decisão estratégica por analogias. Essa característica vem da construção de modelos mentais que permitem a combinação das escolhas estratégicas com a compreensão do ambiente de negócios (GARY; WOOD; PILLINGER, 2012).

Por fim, observa-se a formação de uma postura mais confiante, também resultado das experiências vivenciadas ao longo do exercício da atividade de diretor do alto escalão. Uma postura mais confiante é necessária ao indivíduo no momento de se manifestar durante as reuniões do conselho, para que gere confiança ao board e aos investidores que representam (CLARK; MAGGITTI, 2012).

De outro modo, a teoria do alto escalão destaca a obtenção de informações relevantes como uma demanda relevante dos membros do nível executivo (EISENHARDT, 1989). Com uma maior quantidade de informações, os diretores são capazes de desenvolver mais alternativas para resolver conflitos e buscar a integração entre decisões estratégicas e planos táticos, dando velocidade à tomada de decisão.

O conhecimento do ambiente econômico, político e social e dos negócios da empresa são componentes que também aparecem na teoria do alto escalão. Esses componentes se apresentam como influenciadores no embasamento para a tomada de decisão estratégica (PAPADAKIS; BARWISE, 2002).

No mesmo estudo Papadakis e Barwise (2002) verificaram que a posse de informações sobre os ambientes já mencionados, torna os membros do alto escalão mais ousados durante o processo decisório. Ainda segundo esses autores, essa característica pode afetar positivamente os resultados organizacionais. A posse de informações está relacionada à capacidade de se obter dados com maior riqueza de detalhes e robustez. Segundo Garbuio, Lovallo e Sibony (2015) a riqueza de detalhes e a robustez dos dados permitem melhor análise das informações, influenciando de maneira positiva e direta a eficácia e o resultado das decisões estratégicas. Como outro recurso capaz de orientar a tomada estratégica, a teoria do alto escalão também aponta a intuição como uma ferramenta eficaz (ELBANNA; IBANNA; CHILD; DAYAN, 2013). Para os autores a intuição faz parte de um processo mental capaz de produzir um julgamento a ser utilizado no momento de decidir.

Como última contribuição oriunda da teoria do alto escalão está o diálogo imparcial e desinteressado. Segundo Garbuio, Lovallo e Sibony (2015), o diálogo imparcial e desinteressado é uma característica que traz consigo a qualidade na discussão no momento de se construir cenários futuros, necessários à tomada de decisão estratégica.

Os autores propõem a discussão aberta entre os diretores do alto escalão sobre os pontos positivos e negativos e as incertezas dos dados coletados, bem como das práticas propostas necessárias para explicar a efetividade das decisões.

Como exposto no início dessa sessão, a teoria do alto escalão parte do pressuposto que as características dos diretores do todo podem contribuir com a tomada de decisão estratégica e com 0 desempenho organizacional.

De maneira semelhante, o IBGC (2015) entende que a diversidade de perfis dos Conselheiros de Administração permite maior qualidade e segurança dos processos de tomada de decisão, contribuindo com o desempenho do conselho e empresarial.

Com esse intuito e a fim de complementar a teoria do alto escalão, na próxima seção são revisitadas diversas pesquisas sobre as características individuais necessárias ao conselheiro de administração para exercício de sua atividade.

\section{Diversidade de Perfis dos Conselheiros de Administração}

A falta de uma composição diversificada de perfis na composição dos conselhos de administração pode limitar sua capacidade de atuação, no que diz respeito a assuntos estratégicos como a compreensão das demandas dos mercados e os interesses dos acionistas. Sob esse contexto e a fim de atingir os propósitos 
organizacionais, as empresas estão rompendo com o pragmatismo imposto pelo padrão de perfil e optando pela diversidade de conhecimentos e experiências (CHARAN, 2007; WAGNER, 2015; COULSON-THOMAS, 2009).

Por diversidade de características individuais, a revisão da literatura trouxe como necessárias ao conselheiro de administração a boa formação acadêmica, boa formação específica em governança corporativa, a liderança estratégica, o background político, board interlocking, diversificação de gêneros e postura íntegra. Essas características têm peculiaridades que podem promover o aprofundamento do entendimento sobre as responsabilidades do conselheiro e do conselho (PURDY, LAWLESS, 2012; BHAT; CHEN; JEBRAN; MEMON, 2019; AI MATARI, 2019; KACANSKI, 2019).

A formação intelectual, acadêmica ou específica, que possa abranger por exemplo a governança corporativa dos conselheiros contribui para manter um padrão elevado de discussão e a correta compreensão dos assuntos tratados durante as reuniões do Conselho de Administração (DARMADI, 2013).

Ressalta-se, que por se tratar de um colegiado, a composição do board precisa contar com indivíduos que possuam atributos como consciência de união, envolvimento e aprendizagem, além de atributos de líderes gerenciais (FREIRE et al., 2015). Tais atributos contribuem para reforçar aa coesão do grupo e implementação de decisões estratégicas de longo prazo, garantindo o futuro da organização por meio dos resultados apresentados.

O ambiente político também influência o desempenho organizacional e dessa forma, torna-se crucial que a composição do board conte com conselheiros com background político, uma característica que pressupõe-se que a empresa possui estratégias voltadas à redução de assimetrias de informações e à minimização de incertezas em relação ao ambiente (CAMILO; MARCON; BANDEIRA-DE-MELLO, 2012). Segundo Camilo, Marcon e Bandeira-de-Mello (2012) a conectividade com o ambiente político aumenta o valor da empresa, uma vez que elas fazem uso mais intenso dessa conectividade em períodos de maior incerteza política. Para os autores, o uso da conectividade política é também percebido pelo mercado e refletem positivamente nos indicadores relacionados à redução de risco e à incerteza.

No que tange à participação em vários conselhos, conhecido como board interlocking, observa-se que o conselheiro dotado dessa característica tem acesso à troca de experiências entre diversos conselheiros de administração durante as reuniões. Essa interação entre os conselheiros favorece o desempenho do conselho (PUGLIESE; NICHOLSON; BEZEMER, 2015). Assim, é pertinente observar que o exercício da atividade de conselheiro de administração não se limita a participar de um único conselho. Os benefícios do board interlocking estão presentes na aquisição de experiências e no desenvolvimento das competências individuais dos conselheiros (SANTOS; SILVEIRA, 2007).

O gênero que configura uma característica nominal é vista como relevante à diversificação na composição do board, uma vez que, segundo pesquisas de Dunn (2012), Mathisen, Ogaard e Marnburg (2013) e Silva e Magem (2015) as mulheres possuem conhecimento especializado ou específico da empresa além de possuir a capacidade de expor seus pontos de vista e suas competências de maneira diferente dos homens, o que faz melhorar as capacidades e o desempenho do conselho.

Por fim, temos a consciência ética, que surge como uma característica individual, essencial ao exercício da atividade de conselheiro de administração. A postura íntegra congrega a coragem e a adesão a valores e princípios morais, atributos que podem salvar uma empresa e sua reputação, segundo propõe Coulson-Thomas (2009).

A ausência de integridade vai de encontro às boas práticas de governança corporativa e desperta a desconfiança dos investidores, ocasionando a perda de investimentos (COULSON-THOMAS, 2009). Ainda de acordo com esse autor, o comportamento íntegro dos conselheiros demonstra o comprometimento com a empresa, o engajamento em monitorar o cenário de negócios, a disposição para enfrentar desafios e a valorização da liderança.

\section{Aspectos Metodológicos}

Esta pesquisa de perspectiva qualitativa adota o caráter exploratório para conhecer as características individuais relevantes à atividade de conselheiro de administração independente. O caráter exploratório tem sua justificativa na possibilidade de se interpretar os fenômenos e os significados do objeto de pesquisa atribuídos pelo indivíduo (CRESWELL, 2014).

O método utilizado para conhecer os aspectos subjacentes das experiências vivenciadas pelo sujeito da pesquisa, ao longo de sua trajetória profissional como diretor do alto escalão, é a história oral, que permite obter informações sobre o todo, remetendo ao objeto de pesquisa e que os dados sejam checados e confrontados com outras fontes disponíveis (HAGUETTE, 2011)

Quanto às experiências vivenciadas, elas são relevantes uma vez que é possível perscrutar os aspectos subjacentes que são de interesse desse estudo, e que podem estar nos diferentes significados que cada indivíduo dá àquelas, e que podem ser desvelados de forma reflexiva no momento da análise dos dados (SILVA, 2010). 
Por sua vez, os significados podem ser compreendidos a partir das especificidades que fazem parte de um contexto amplo, em se inserem a própria vida do sujeito, o tempo, as experiências passadas, 0 retrospecto, a comunicação e interação humana (SILVA, 2010).

Para atingir o proposto pela história oral, os discursos dos entrevistados foram orientados a partir de um roteiro padronizado com questões ordenadas e respostas abertas, as quais possibilitaram 0 aprofundamento nos temas relacionados ao objeto estudado (TRIVIÑOS, 2015).

Para a escolha dos entrevistados optou-se por uma amostragem não aleatória, conforme propõe a história oral (HAGUETTE, 2011), em que foram selecionados 30 membros de conselhos de administração, sendo 15 presidentes e 15 Conselheiros de Administração independentes.

Todos os entrevistados fazem parte de um total de 15 empresas com estrutura de governança corporativa, listadas no Novo Mercado, da B3 e dos setores de produção e serviços, localizadas na região Sul e Sudeste. Esse recorte se configurou em decorrência da disposição das agendas dos entrevistados. Os participantes da pesquisa foram entrevistados no período de julho a novembro de 2017, totalizando aproximadamente 32 horas de gravações e 600 páginas transcritas.

\subsection{Coleta de Dados}

A coleta de dados foi orientada por meio de roteiro estruturado em relação aos pontos de interesse, contudo deixando as respostas abertas, o que permitiu aos entrevistados liberdade em seus discursos, possibilitando a obtenção de informações ricas em experiências vivenciadas pelos indivíduos (SILVA, 2010).

O roteiro de entrevista foi construído com o objetivo de extrair em profundidade, opiniões sobre quais características individuais de conselheiro de administração seriam mais relevantes ao exercício da atividade.

A seguir são apresentados no Quadro 1 as características que emergiram da revisão da literatura que combinam estudos concentrados na diversidade dos perfis dos conselheiros de administração com a teoria do alto escalão.

\begin{tabular}{|c|c|}
\hline CARACTERISTICAS ORIENTADORAS DA PESQUISA & AUTORES \\
\hline $\begin{array}{l}\text { Competências requeridas do Conselheiro de } \\
\text { Administração }\end{array}$ & $\begin{array}{l}\text { Goetz, 2006; Brown, 2007; IBGC, 2009; Coulson-Thomas, 2009; } \\
\text { Oliveira, 2011; Nadler, 2004; Kaczmarek; Kimino; Pye, 2012; IBGC, } \\
2015 .\end{array}$ \\
\hline Formação Acadêmica & Amann, 2010; Oliveira, 2011; Darmadi, 2013 \\
\hline Gênero & Dunn, 2012; Mathisen; Ogaard; Marnburg, 2013; Silva; Magem, 2015. \\
\hline Idade & Hambrick; Mason, 1984. \\
\hline Alcance de Resultados & $\begin{array}{l}\text { Não foram encontradas na literatura, pesquisas sobre mensuração de } \\
\text { resultados de Conselheiros de Administração e seus resultados } \\
\text { alcançados. }\end{array}$ \\
\hline Reconhecimento no Mercado & Camilo; Marcon; Bandeira-De-Mello, 2012. \\
\hline Trajetória e Acúmulo de Experiências & Gary; Wood; Pillinger, 2012. \\
\hline Competência na Comunicação & Garbuio; Lovallo; Sibony, 2015; Pugliese; Nicholson; Bezemer, 2015 \\
\hline Conhecimento do Ambiente Interno de Negócios & Mrad; Hallara, 2012. \\
\hline Conhecimento da Realidade Internacional e Nacional & Charan, 2007; Wagner, 2015. \\
\hline Habilidade em Análise & Eisenhardt,1989; Clark; Maggitti, 2012. \\
\hline Habilidade para Negociar & Garbuio, Lovallo, Sibony, 2015. \\
\hline Atuação Independente & $\begin{array}{l}\text { Rodrigues; Brandão, 2010; Liang, Xu; Jiraporn, 2013; Vesco e Beuren, } \\
\text { 2016. }\end{array}$ \\
\hline Credibilidade, Valores Éticos e Morais & Coulson-Thomas, 2009. \\
\hline Disposição a Cooperar & $\begin{array}{l}\text { Não foram encontradas na literatura, pesquisas sobre disposição a } \\
\text { cooperar por Conselheiros de Administração. }\end{array}$ \\
\hline Liderança entre Iguais & Freire et al., 2015. \\
\hline Postura Proativa & $\begin{array}{l}\text { Não foram encontradas na literatura, pesquisas sobre postura proativa } \\
\text { por parte dos Conselheiros de Administração. }\end{array}$ \\
\hline Tomada de Decisão & Clark; Maggitti, 2012; Elbanna; Child; Dayan, 2013. \\
\hline Participação em vários conselhos & $\begin{array}{l}\text { Pugliese; Nicholson; Bezemer, 2015; Santos, Silveira, 2007; Vesco; } \\
\text { Beuren, 2016. }\end{array}$ \\
\hline $\begin{array}{l}\text { Características mais importantes ao conselheiro de } \\
\text { administração }\end{array}$ & $\begin{array}{l}\text { Hambrick; Mason, 1984; Finkelstein; Hambrick, 1990; Coulson- } \\
\text { Thomas, 2009; Rodrigues, Brandão, 2010; Gary, Wood, Pillinger, } \\
\text { 2012; Liang, Xu, Jiraporn, 2013; Vesco, Beuren, 2016. }\end{array}$ \\
\hline
\end{tabular}

Fonte: Elaboração própria.

A revisão apresentada foi realizada com o objetivo de correlacionar estudos pertinentes à Teoria do Alto Escalão e a diversidade dos perfis dos conselheiros de administração. Ambas as perspectivas de estudos apresentam aspectos que direcionaram a pesquisa junto aos entrevistados, a fim de possibilitar um constructo teórico que contemplasse um perfil com as características individuais relevantes à atividade de conselheiro de administração.

Com isso, pretendeu-se seguir com rigor o que é exigido em pesquisas guiadas pela história oral, em que os depoimentos são considerados como um conjunto que informa o todo e que remete ao objeto de pesquisa, permitindo que os dados fossem checados e confrontados com outras fontes disponíveis (HAGUETTE, 2011). 


\subsection{Técnica de Análise de Dados}

Em alinhamento com a proposta metodológica para essa pesquisa, a análise de conteúdo foi a técnica recomendada para o tratamento dos dados. A utilização da análise de conteúdo permite conhecer aspectos subjacentes contidos nos discursos dos participantes da pesquisa, considerando as significações e, eventualmente, a sua forma, conforme prescreve Bardin (2011).

Segundo Bardin (2011), a análise de conteúdo visa ao conhecimento de variáveis de ordem psicológica, sociológica, histórica, construída por meio de um mecanismo de dedução e com base em reconstruções feitas a partir de uma amostra de palavras. Por meio da análise de conteúdo, os discursos após transcritos foram analisados a partir da associação de palavras, codificação de excertos com a finalidade de alcançar o objetivo da pesquisa.

Bardin (2011) descreve a fases da análise de conteúdo como tendo início na pré-análise, que consiste na leitura flutuante ou prévia que se faz dos documentos a fim de extrair impressões e opiniões iniciais. Em seguida, ainda segundo a autora, ocorre a escolha dos documentos, a constituição do corpus da pesquisa, a preparação do material, as regras de recorte, categorização e codificação.

Por fim, tem-se o tratamento dos resultados, dos quais surgirão as inferências e a interpretação dessas, culminando em se revelar os aspectos subjacentes que emergem da pesquisa, destaca Bardin (2011).

É pertinente ressaltar que foi utilizado para a análise de conteúdo, o software Atlas T.I.8, library. Em seguida são descritos no Quadro 2, o mapa que direciona a pesquisa na busca pelas características relevantes ao conselheiro de administração, para o exercício da atividade.

\begin{tabular}{|c|c|c|}
\hline Formação Acadêmica & \multirow{3}{*}{ Aspectos nominais } & \multirow{3}{*}{$\begin{array}{l}\text { Dados sociais e de } \\
\text { instrução do indivíduo. }\end{array}$} \\
\hline Gênero & & \\
\hline Idade & & \\
\hline Alcance de Resultados & \multirow{2}{*}{$\begin{array}{l}\text { Aspectos relacionados à } \\
\text { atividade de conselheiro de } \\
\text { administração }\end{array}$} & \multirow{2}{*}{$\begin{array}{l}\text { Trajetória profissional } \\
\text { dentro da atividade de } \\
\text { diretor de alto escalão. }\end{array}$} \\
\hline $\begin{array}{l}\text { Reconhecimento no Mercado } \\
\text { Trajetória e Acúmulo de Experiências }\end{array}$ & & \\
\hline Competência na Comunicação & \multirow{5}{*}{ Aspectos cognitivos } & \multirow{5}{*}{$\begin{array}{l}\text { Capacidade de influenciar } \\
\text { e utilizar as competências } \\
\text { para reconhecer as } \\
\text { oportunidades (CHARAN, } \\
\text { 2007). } \\
\text { Capacidades sob a forma } \\
\text { de conhecimentos (RUAS, } \\
2008 \text { ). }\end{array}$} \\
\hline Conhecimento do Ambiente Interno de Negócios & & \\
\hline Conhecimento da Realidade Internacional e Nacional & & \\
\hline Habilidade em Análise & & \\
\hline Habilidade para Negociar & & \\
\hline Atuação Independente & \multirow{5}{*}{ Aspectos comportamentais } & \multirow{5}{*}{$\begin{array}{l}\text { Conhecimento mobilizado } \\
\text { na prática profissional. } \\
\text { Foco nos valores e } \\
\text { processos organizacionais } \\
\text { (LE BOTERF, 2016). }\end{array}$} \\
\hline Credibilidade, Valores Éticos e Morais & & \\
\hline Disposição a Cooperar & & \\
\hline Liderança entre Iguais & & \\
\hline Postura Proativa & & \\
\hline
\end{tabular}

Fonte: Elaboração própria.

O quadro 2, tem por objetivo relacionar o encadeamento das características individuais relevantes ao Conselheiro de Administração com os aspectos nominais, atividades, cognitivos e comportamentais, oriundos da Revisão da Literatura. Os aspectos nominais estão relacionados diretamente aos dados sociais e de instrução do indivíduo, que são observados no momento da indicação do conselheiro de administração. Não obstante, os aspectos relacionados à atividade de conselheiro de administração, a importância desse item está em conhecer a atuação do diretor de alto escalão ao longo de sua trajetória profissional.

Os aspectos cognitivos se relacionam com a capacidade de influenciar e utilizar as competências para reconhecer as oportunidades, cultivar relacionamentos e analisar informações demonstrando 0 desenvolvimento de capacidades sob a forma de conhecimentos (CHARAN, 2007; RUAS, 2008). Por fim, os aspectos comportamentais referem-se à mobilização do conhecimento na forma de prática profissional, em que o foco recai sobre os valores e processos organizacionais (LE BOTERF, 2016).

\section{Apresentação e Discussão dos Resultados}

Nesta seção são apresentados e discutidos os achados acerca das características individuais necessárias ao Conselheiro de Administração. Vale ressaltar que essas características se apresentaram com graus de relevância diferenciados, na percepção dos entrevistados, conforme ilustra o Quadro 3.

No quadro 3 constam os apontamentos dos entrevistados em relação a relevância de cada característica apresentada. Os entrevistados citaram que todas as características são relevantes, com exceção de atuação independente e da credibilidade. A trajetória e acúmulo de experiências podem ser aprendidas ou adquiridas, assim que o indivíduo passa a exercer a atividade de conselheiro. 
Quadro 3 - Características mais relevantes, segundo os entrevistados, ao perfil do Conselheiro de Administração independente

\begin{tabular}{|c|l|l|}
\hline $\begin{array}{c}\text { Indicação de } \\
\text { Relevância }\end{array}$ & \multicolumn{1}{|c|}{ Entrevistados } & \multicolumn{1}{c|}{ Características } \\
\hline 6 & $\mathrm{C} / 15, \mathrm{C} / 5, \mathrm{C} / 6, \mathrm{C} / 9, \mathrm{P} / 3, \mathrm{P} / 8$ & Atuação independente \\
\hline 7 & $\mathrm{C} / 4, \mathrm{P} / 1, \mathrm{P} / 4, \mathrm{P} / 5, \mathrm{P} / 10, \mathrm{P} / 11, \mathrm{P} / 14$. & Credibilidade \\
\hline 1 & $\mathrm{P} / 7$ & Conhecimento do ambiente de negócio da empresa. \\
\hline 1 & $\mathrm{P} / 15$ & Habilidade para negociador. \\
\hline 2 & $\mathrm{C} / 8, \mathrm{C} / 3$ & Postura proativa. \\
\hline 1 & $\mathrm{C} / 14$ & Tomada de decisão. \\
\hline 6 & $\mathrm{C} / 1, \mathrm{C} / 2, \mathrm{P} / 1, \mathrm{P} / 12, \mathrm{P} / 13, \mathrm{P} / 6$ & Trajetória e o acúmulo de experiências. \\
\hline
\end{tabular}

Fonte: Elaboração própria.

Observou-se nas citações dos entrevistados que a credibilidade faz parte da postura e do caráter da pessoa e por ser algo intrínseco, já vem com o indivíduo. Já a trajetória profissional se apresentou como crucial na indicação de um conselheiro, devido ao acúmulo de experiências. Na percepção dos entrevistados é a "bagagem" do indivíduo que faz com que possa contribuir para desempenho do conselho.

Nas próximas subseções são discutidos os resultados das pesquisas e as opiniões dos entrevistados à luz da revisão da literatura. Os resultados apresentam de maneira detalhada as características de atuação independente, credibilidade e trajetória e acúmulo de experiências, consideradas como essenciais ao conselheiro de administração. As demais características são comentadas de modo pertinente ao final da discussão e apresentação dos resultados.

\subsection{Atuação Independente}

Nessa seção, os resultados apresentados estão relacionados à característica de Atuação Independente. A partir da análise de conteúdo, foi possível elencar as seguintes frases que melhor ilustram essa característica, conforme Quadro 4.

\begin{tabular}{|c|c|}
\hline ENTREVISTADO & PENSAMENTO \\
\hline $\mathrm{C} / 2$ & $\begin{array}{l}\text { O conselheiro tem que ter a capacidade de discordar. [...] tem que ter autonomia, liberdade e coragem } \\
\text { intelectual de expor uma opinião diferente }\end{array}$ \\
\hline $\mathrm{C} / 4$ & $\begin{array}{c}\text { Conselheiro vaca de presépio? Que participa apenas pra compor a mesa? Eu pelo menos não me } \\
\text { proponho a isso! Se eu não puder expor as minhas ideias, se eu não puder colocar ponto de vista, acho } \\
\text { que não estarei contribuindo. }\end{array}$ \\
\hline $\mathrm{C} / 8$ & $\begin{array}{l}\text { Em outros conselhos, a discussão não está na sua esfera de decisão. A decisão é prévia ao próprio } \\
\text { conselho. É uma realidade bastante comum. Tem conselheiros que estão para votar aquilo que foi } \\
\text { decidido pelo majoritário }\end{array}$ \\
\hline $\mathrm{C} / 9$ & $\begin{array}{l}\text { O conselheiro independente tem que ter coragem de falar o que pensa! [...] estar aberto para mudar de } \\
\text { opinião, porque às vezes, você fica em uma linha e não consegue ver que tem outro caminho ali do lado, } \\
\text { então essa atuação independente é uma arte. }\end{array}$ \\
\hline $\mathrm{P} / 1$ & $\begin{array}{c}\text { O conselheiro que representa um terceiro precisa se despir da representação. Se ele não fizer isso, tem } \\
\text { um problema grave, e, nesse aspecto, independência é a 'chave'. Você precisa fazer o que é melhor } \\
\text { para a empresa }\end{array}$ \\
\hline $\mathrm{P} / 12$ & $\begin{array}{l}\text { Às vezes a pessoa entra ali meio sem coragem, meio constrangida, meio acanhada. Mas... Em algum } \\
\text { momento ele vai ter que tomar alguma decisão. }\end{array}$ \\
\hline $\mathrm{P} / 2$ & $\begin{array}{l}\text { Quando um assunto está desconfortável para um conselheiro, a gente estuda mais, porque a gente } \\
\text { respeita. Não quer dizer que ele está errado, pode ser que esteja certo e os outros errados. }\end{array}$ \\
\hline
\end{tabular}

Fonte: Elaboração própria.

A postura independente é um comportamento esperado de todos os conselheiros de administração, mesmo que possam ir de encontro aos interesses dos grupos que representam, conforme ilustram as citações do Quadro 4. Assim, ter uma postura independente não é uma característica facultativa ao conselheiro, mas obrigatória.

Infere-se que a Atuação Independente é uma qualidade que denota coragem e respeito aos investidores e à companhia e que não se deve beneficiar um "terceiro" $(\mathrm{P} / 1)$ em detrimento da empresa. Esse resultado corrobora a pesquisa de Rodrigues e Brandão (2010) quando afirmam que o conselheiro precisa tomar suas decisões de maneira clara, assertiva e com imparcialidade. Com isso, demonstra-se sua independência em relação ao grupo que o indicou, a fim de não comprometer as decisões de maior relevância estratégica, para beneficiar apenas uma das partes.

E importante observar que o posicionamento imparcial não desqualifica o conselheiro e nem representa um desserviço à empresa. Ao contrário, demonstra sua capacidade e respeito àqueles que o indicaram. Isso porque ao discordar das propostas apresentadas, o conselheiro não está se voltando contra um determinado grupo. Desde que o conselheiro entenda que a companhia possa ser prejudicada pela aprovação de determinado projeto, seu foco deve ser em preservar os interesses dos stakeholders. Esse achado se alinha com os estudos de Oliveira (2011), que afirma que a livre atuação do Conselheiro de Administração permite executar plenamente suas atribuições com responsabilidade, evitando atritos entre gestão e controle. Para Vesco e Beuren (2016), um Conselho de Administração caracterizado como independente tende a uma 
melhor reputação perante o mercado e investidores.

\subsection{Credibilidade, Valores Éticos e Morais}

Quanto à credibilidade, valores éticos e morais, não se observou nas entrevistas um meio termo que substitua tais valores. O Quadro 5 ilustra que o Conselheiro deveria ter credibilidade, valores éticos e morais, caso contrário não haveria espaço como membro do conselho de administração.

Quadro 5: Credibilidade, Valores Éticos e Morais
\begin{tabular}{|c|l|}
\hline ENTREVISTADO & \multicolumn{1}{c|}{ PENSAMENTO } \\
\hline C/2 & $\begin{array}{l}\text { Você tem que ter credibilidade no conselho e perante os seus superiores, que são os acionistas } \\
\text { controladores. Eles têm que confiar em você. Os outros conselheiros também têm que ter respeito e } \\
\text { têm que reconhecer o comportamento ético e moral. Não se pode ter um conselho em que um } \\
\text { desconfia do outro. }\end{array}$ \\
\hline C/7 & $\begin{array}{l}\text { Eu não consigo imaginar um conselheiro que não tenha essa credibilidade, quer dizer, que ele tenha } \\
\text { que sentar em uma mesa de iguais, e lidando com o grupo executivo, e que haja algum tipo de dúvida, } \\
\text { algum tipo de suspeita com relação a seus valores éticos e morais. }\end{array}$ \\
\hline C/11 & $\begin{array}{l}\text { Tem que ter vida familiar íntegra. Acabar com essa malandragem que a gente vê aos montes. Isso é } \\
\text { fundamental, então família é importante para te dar o reconhecimento e respeito. }\end{array}$ \\
\hline P/4 & $\begin{array}{l}\text { A hora que tiver um arranhãozinho, dificilmente ele vai ser contratado. Vai ter que se explicar bastante. } \\
\text { Às vezes o cara não teve culpa. Não estava envolvido, mas infelizmente, se o nome dele estiver } \\
\text { atrelado a alguma coisa errada, o mercado não perdoa. }\end{array}$ \\
\hline P/5 & $\begin{array}{l}\text { A credibilidade do conselheiro, os valores éticos e morais são tão importantes quanto para um } \\
\text { executivo ou qualquer outro quadro de pessoa importante. Porque ele estará representando a } \\
\text { empresa. Além de estar aqui decidindo pela empresa. Sabendo da responsabilidade dele em manter } \\
\text { sigilo sobre certas questões. }\end{array}$ \\
\hline P/9 & $\begin{array}{l}\text { A sua vida pessoal conta muito. Nós temos um programa de compliance aqui fortíssimo. O histórico } \\
\text { ético dessa pessoa, seus feitos e postura profissional passada sempre contam. Qualquer postura fora } \\
\text { do nosso programa de compliance ou de postura pessoal faz ser automaticamente excluído. }\end{array}$ \\
\hline
\end{tabular}

Fonte: Elaboração própria.

A partir das citações dos entrevistados, contidas no Quadro 5, percebe-se que a conduta ilibada se caracteriza como um atributo sine qua non ao perfil do candidato a Conselheiro de Administração. Os resultados da pesquisa demonstram que a conduta ética e moral tem sido alvo recorrente de várias discussões, devido aos escândalos em grandes empresas privadas e públicas, em que Conselhos de Administração estiveram envolvidos em atos de corrupção.

Por isso abordar tal assunto, na forma de característica relevante à escolha do Conselheiro de Administração independente é tão oportuna. É inerente à responsabilidade do Conselho de Administração zelar para que a companhia obedeça a princípios éticos e morais, posicionamento enfatizado por todos os entrevistados. Essa perspectiva, que vem da análise das citações dos entrevistados vai ao encontro das pesquisas de Claessens (2003); Coulson-Thomas (2009) e Purdy e Lawless (2012).Os autores destacam em seus estudos que 0 desrespeito às práticas de governança contaminam princípios, comprometem o desempenho da empresa e cria desconfiança aos investidores quanto à percepção de risco no investimento.

Das citações dos entrevistados, depreende-se que o conselheiro de administração tem que zelar por sua conduta, uma vez que o mercado não "perdoa" comportamentos desonestos e inescrupulosos. Isso porque tais comportamentos representam prejuízos à imagem da empresa e evasão de capital, comprometendo projetos futuros e consequentemente o crescimento organizacional. $O$ resultado é corroborado pelos estudos de Coulson-Thomas (2009) quando afirma que o compromisso com a legalidade e uma postura íntegra são fundamentais aos princípios de governança e à criação de valor, pois são reconhecidos pelo mercado e necessários à sobrevivência do negócio. Para Coulson-Thomas (2009), o comportamento íntegro dos conselheiros demonstra o valor que dão à empresa e à compreensão do que está acontecendo no ambiente de negócios, além da disposição em confrontar realidades.

Por fim, esses achados observados no Quadro 5 são também sustentados por Rodriguez e Brandão (2010), pois em seus estudos apontam que não há como o conselho manter em seu quadro alguém que inspire desconfiança aos acionistas ou à administração.

\subsection{Trajetória e Acúmulo de Experiências}

A trajetória e o acúmulo de experiências representam uma característica que se revelou um atributo obrigatório ao perfil do conselheiro de administração, da qual as demais características dependem para tornarem-se determinantes à escolha do candidato. É importante ressaltar que as experiências adquiridas ao longo da trajetória profissional do conselheiro e permitem a ele um melhor desempenho e maior contribuição junto ao conselho, conforme ilustra o Quadro 6.

Conforme ilustram as citações do Quadro 6, a trajetória e o acúmulo de experiências são primordiais no momento da indicação do conselheiro de administração. A única exceção que pode substituir a experiência é a especialização, entendida como o domínio de uma determinada área do conhecimento. Essa condição só 
se justifica quando estritamente necessária em um dado momento e por exigência imposta pela estratégia adotada pela empresa.

Quadro 6: Trajetória e o acúmulo de experiências

\begin{tabular}{|c|l|}
\hline ENTREVISTADO & \multicolumn{1}{c|}{ PENSAMENTO } \\
\hline C/1 & $\begin{array}{l}\text { A única exceção é que algumas pessoas que ainda são juniores, mas têm forte profundidade em finanças, } \\
\text { por exemplo. Elas têm utilidade como membro do conselho. }\end{array}$ \\
\hline C/2 & $\begin{array}{l}\text { Acredito que 90\% dos conselheiros são escolhidos baseados na trajetória e no acúmulo de experiências. } \\
\text { Seja como conselheiro, como diretor de empresas e eventualmente como profissional liberal. }\end{array}$ \\
\hline $\mathrm{C} / 3$ & $\begin{array}{l}\text { Para desempenhar seu papel no Conselho de Administração, você tem que ter vivência profissional que } \\
\text { te permita isso, senão é apenas uma opinião. }\end{array}$ \\
\hline $\mathrm{C} / 5$ & $\begin{array}{l}\text { A pessoa pode ter uma formação até frágil, mas se tiver experiências acumuladas de participação em } \\
\text { outros conselhos, isso acrescenta muito. }\end{array}$ \\
\hline $\mathrm{P} / 2$ & $\begin{array}{l}\text { A gente tem aqui pessoas que tiveram boa trajetória de resultados, pessoas que construíram esses } \\
\text { resultados com base em uma gestão reconhecida, de qualidade de pessoas, de modelo de gestão, na } \\
\text { área financeira, em processos de aquisição, então isso tudo compõe. }\end{array}$ \\
\hline $\mathrm{P} / 11$ & $\begin{array}{l}\text { Não adianta um cara sem experiência. Contratar achando que vai aprender é um risco muito grande às } \\
\text { decisões do conselho. }\end{array}$ \\
\hline $\mathrm{P} / 12$ & $\begin{array}{l}\text { Conhecer o que o conselheiro realizou, por onde passou, os setores em que transitou, que tipo de } \\
\text { experiências resultaram dessa trajetória, é um elemento importante. A experiência como executivo e em } \\
\text { setores diversos amplia o horizonte de relacionamento. }\end{array}$ \\
\hline P/15 & $\begin{array}{l}\text { Não tem experiência como conselheiro e às vezes como homem de negócios ou como CEO, não tem essa } \\
\text { experiência, mas ele tem uma experiência digital, então eu diria para você o seguinte, na mescla do } \\
\text { conselho, de alguns eu preciso de background, de outros não. }\end{array}$ \\
\hline Fonte: Elaboração própria &
\end{tabular}

Os achados na pesquisa demonstram que é necessário que o conselheiro tenha experimentado erros e acertos e aprendido com ambos, forjando assim um perfil contributivo ao conselho. Os resultados também revelam que as experiências auxiliam na análise estratégica e na tomada de decisão, e que sua ausência pode representar um risco ao processo de tomada de decisão. Esse achado é corroborado Hambrick e Mason (1984) ao observarem que a experiência permite maior assertividade na tomada de decisão estratégica. Conforme afirmam Gary, Wood e Pillinger (2012) e Clark e Maggitti (2012), as citações do Quadro 7 são representativas da importância da vivência profissional que enriquece o currículo do conselheiro de administração e o capacita a enfrentar situações complexas.

Observou-se também durante a pesquisa algumas características que embora não tenham sido apontadas como essenciais pelos entrevistados, quando reunidas em um mesmo perfil, contribuem para o alinhamento do conselheiro às exigências do conselho, do que quando encontradas separadamente e que são apresentadas a seguir.

\subsection{Características Sociodemográficas}

A formação acadêmica, gênero e idade foram configuram características sociais de cada indivíduo e foram apresentadas individualmente aos entrevistados, que as consideraram como não determinantes à escolha do conselheiro. Os achados mostraram que a formação acadêmica não é determinante à escolha do conselheiro de administração, a não ser que esteja relacionada a um conhecimento específico, necessário ao conselho, ou se estiver acrescida de experiência profissional. Importante esclarecer que, apesar de não determinante, a falta da formação acadêmica impõe dificuldades ao conselheiro no momento de realizar as análises que são de sua competência e no momento de participar das discussões para tomada de decisão.

Pesquisas de Darmadi (2013), a despeito do que pensam os entrevistados, mostram que a formação intelectual dos conselheiros auxilia na manutenção de um padrão de discussão, que permite a correta compreensão dos assuntos tratados durante as reuniões do conselho de administração.

Na mesma linha, Amann (2010) vê a formação acadêmica como um diferencial ao conselho, capaz de torná-lo mais profissional, transparente e com melhor performance. Não obstante, os entrevistados nesta pesquisa enfatizaram que esse quesito de formação acadêmica não é essencial ao papel de conselheiro.

No caso de gênero, verificou-se a mesma situação observada com a formação acadêmica. Para os entrevistados, ser homem ou mulher é indiferente, o que é relevante é a qualificação, a experiência e a capacidade de contribuir com o Conselho de Administração.

Contudo, Dunn (2012); Mathisen; Ogaard e Marnburg (2013); Silva e Magem (2015) consideram que as mulheres possuem a capacidade de expor suas ideias e competências de maneira diferente dos homens, o que eleva a capacidade dos conselhos, auxiliando no desempenho do conselho e no processo de tomada de decisão. Nesse sentido, a maior participação de mulheres nos conselhos poderia ser estimulada, conforme preconizam esses autores.

Quando abordada a questão da idade, essa se mostra como relevante se atrelada à experiência profissional. Esse achado achado é corroborado por Hambrick e Mason (1984) que veem a idade como um condutor à maturidade, tornando o conselheiro de administração mais ponderado e responsável no momento de participar das reuniões do colegiado. 


\subsection{Características relacionados à atividade de conselheiro de administração}

A seguir são apresentados os achados referentes à atividade de conselheiro de administração, em que estão contidas as características intituladas de alcance de resultados obtidos e o reconhecimento no mercado, que são aspectos da trajetória profissional do diretor de alto escalão.

A característica alcance de resultados foi proposta com o objetivo de saber se o desempenho do indivíduo, ao longo do tempo em que exerceu a atividade de conselheiro de administração foi relevante em seu perfil. Os resultados mostraram que o alcance de resultados é uma característica relevante, contudo, segundo com os entrevistados, difícil de ser comprovada. Isso se dá pela impossibilidade de atribuir ao conselheiro de maneira individual, prejuízos ou lucros à empresa, pois as decisões pertencem ao colegiado.

Entretanto, caso deseje-se mensurar tal característica, a maneira mais indicada é por meio de informações obtidas junto ao mercado, que remete ao reconhecimento no mercado, próxima característica a ser abordada.

Os resultados encontrados indicam que ser reconhecido pelo mercado é uma maneira de responder parcialmente à questão do desempenho e do alcance de resultados, pois está relacionado diretamente com o desempenho do diretor de alto escalão ao longo de sua trajetória profissional. A relevância dessa característica está na confiança que ela desperta nos acionistas em termos de legitimidade da escolha do conselheiro, uma vez que lhes dá a segurança em ter alguém reconhecido como autoridade na área em que atua, auxiliando o conselho a tomar as melhores decisões.

De outro modo, conselheiros com reconhecimento no mercado, na visão dos entrevistados, apenas emprestam sua imagem e títulos aos conselhos em que participam, sem de fato contribuírem com eles, dada a grande quantidade de conselhos que participam. Mais importante que a imagem e os títulos, os respondentes enfatizaram a participação, a competência e o tempo disponível que o indivíduo pode dar efetivamente ao conselho em que tem cadeira.

$\mathrm{Na}$ revisão da literatura não foram encontrados estudos que apoiassem ou contradissessem os resultados expostos acima, porém, Camilo, Marcon e Bandeira-de-Mello (2012) fazem referência o background político, que muitos conselheiros de administração reconhecidos no mercado possuem. Segundo Camilo, Marcon e Bandeira-de-Mello (2012) o background político representa uma situação favorável aos negócios que estejam sendo realizados e no processo de tomada de decisão, por conta do trânsito político que conselheiros com reconhecimento no mercado têm dentro do governo, o que converge com os achados da pesquisa.

\subsection{Características relacionados ao aspecto cognitivo}

Os aspectos cognitivos estão relacionados, segundo Charan (2007), com a capacidade de o diretor de alto escalão influenciar e utilizar as competências para reconhecer as oportunidades que se apresentam no ambiente de negócios. Ruas (2008) enfatiza que o aspecto cognitivo também se relaciona com as capacidades que se manifestam sob a forma de conhecimentos.

Dentro da perspectiva cognitiva estão as características de competência na comunicação, conhecimento do ambiente interno de negócios, conhecimento da realidade internacional e nacional, habilidade em análise e habilidade para negociar.

A competência da comunicação do conselheiro está relacionada ao saber se manifestar. Os resultados desta pesquisa mostram que o conselheiro de administração precisa saber se comunicar de maneira clara e objetiva, sobre o que pensa e como vê as propostas submetidas durante às reuniões do conselho. Não obstante, também emerge dos achados a necessidade da boa comunicação com os demais membros do board, pois o "não saber se comunicar" pode provocar confusão na exposição dos assuntos que estão sob a responsabilidade do Conselheiro de Administração, provocando divergências e um possível erro estratégico na tomada de decisão.

Os resultados encontrados para as competências da comunicação são corroborados Pugliese, Nicholson e Bezemer (2015). Em sua pesquisa, os autores veem que a comunicação está relacionada à capacidade de expor ideias, em que há a exposição do raciocínio lógico e coerente, sendo o indivíduo capaz de entender e se fazer entender sobre o que pensa, favorecendo com isso um ambiente interativo.

O conhecimento do ambiente interno de negócio da empresa não se revelou como algo urgente e indispensável à escolha do conselheiro de administração, pois o que mais interessa são as experiências e as competências para analisar de forma mais abrangente o ambiente externo. Os achados revelaram que os entrevistados entendem que é necessário que o conselheiro busque conhecer o negócio da empresa ao longo de sua estada no conselho. Na literatura, verificou-se, porém, que o conhecimento sobre o negócio coloca o conselheiro mais próximo da atividade da empresa, permitindo que ele colabore efetivamente nas decisões do conselho (MRAD; HALLARA, 2012). Esse conflito entre o que foi obtido nos achados desta pesquisa e 0 que indica os estudos de Mrad e Hallara (2012) suscita uma reflexão sobre o quão rápido o conselheiro de administração precisa conhecer e entender o ambiente de negócios da empresa, para que possa contribuir de maneira significativa com as decisões do conselho.

No que diz respeito ao conhecimento da realidade internacional e nacional, os resultados indicaram 
que o conselho espera que seus membros estejam a par da geopolítica, para que possam avaliar os movimentos do mercado e as tendências da economia. O conhecimento da realidade internacional e nacional implica na discussão, formulação e validação das estratégias organizacionais a partir de análises adequadas de balanços, cenários, relatórios e contexto mais amplo, conforme evidenciado nos achados da pesquisa. Nesse sentido, verifica-se uma convergência entre os resultados com os estudos de Brown (2007), Charan (2007) e Wagner (2015), que entendem que um conselho de administração bem informado sobre a realidade nacional e internacional é capaz de dar à empresa sustentabilidade e competividade.

Quanto a habilidade em análise dos resultados, observou-se que contempla a capacidade em analisar relatórios, documentos em geral, permitindo o questionamento e domínio de temas complexos e desconhecidos. Esse resultado vai ao encontro dos estudos de Clark e Maggitti (2012), Charan (2007), Wagner (2015) e Eisenhardt (1989). Os autores em suas pesquisas apontam que a realização de análises adequadas de balanços, cenários, relatórios e contexto mais amplo permitem ao conselheiro deliberar e referendar ações estratégicas, criando alternativas capazes de solucionar conflitos e influenciar positivamente a velocidade da tomada de decisão.

A habilidade em negociar está na capacidade de se comunicar tendo na conciliação uma condição crucial. Os resultados também demonstraram que a habilidade em negociar auxilia a tomada de decisões, desde que os posicionamentos estejam fundamentados e sejam interpretados de maneira que possam ser compreendidos entre todos.O estudo de Garbuio, Lovallo e Sibony (2015) complementa o resultado encontrado ao observar que, quando os membros do conselho discutem de maneira articulada as suposições em relação às previsões do resultado de uma decisão a ser tomada, eles estão promovendo o diálogo desinteressado, que propicia a busca por pontos positivos e negativos e as incertezas dos dados coletados, que precisam ser considerados à tomada de decisão.

\subsection{Características relacionados aos aspectos comportamentais}

Os aspectos comportamentais estão relacionados, segundo Le Boterf (2016) ao conhecimento mobilizado na prática profissional, da qual os valores e processos organizacionais fazem parte. Dentro dos aspectos comportamentais estão a disposição a cooperar, a liderança entre iguais, a postura proativa e a tomada de decisão. Lembrando que, dada a relevância, postura independente e credibilidade foram vistas separadamente.

Pode-se inferir a partir dos resultados encontrados que a cooperação é percebida como a interação entre os Conselheiros de Administração e a gestão. Para os entrevistados, trata-se de uma atitude que diminui a distância entre ambos, o que, em um primeiro momento é visto de forma positiva para a organização. Não obstante, para alguns entrevistados a cooperação, apesar de salutar, é preciso ser comedida pois pode causar certo constrangimento ao CEO, que pode interpretar uma cooperação mais constante como ingerência em seu trabalho, gerando conflitos. Nesse sentido, os entrevistados alegam que o conselheiro tem que cooperar sempre com o conselho, todavia, com o grupo executivo tem limite, para não se envolver na operação.

Os resultados também indicaram que cooperar também significa participar de maneira efetiva das reuniões do conselho, demonstrando interesse pelo que está sendo discutido e questionamentos sobre pontos obscuros que poderiam afetar a tomada de decisão. Para essa característica, também não foram encontrados estudos ao longo da revisão da literatura que corroborassem ou contradissessem os achados.

A análise da liderança entre iguais teve como objetivo conhecer a influência e a postura dos demais membros do conselho, durante as reuniões ou no decorrer do processo de tomada de decisão, quando a liderança individual é exercida pelo conselheiro sobre os demais. Os resultados indicaram que a capacidade de liderança não pode ser exercida unilateralmente, em que a vontade de um sobrepuja a dos demais. Ressalta-se que os achados mostraram que a liderança é relevante quando o conselheiro de administração tem legitimidade adquirida por meio do conhecimento sobre o que está sendo discutido ou por sua trajetória profissional. Freire et al. (2015) destaca que a liderança entre iguais é relevante quando o conselheiro se torna um negociador capaz de convencer seus pares e uni-los em torno de um consenso. $O$ resultado encontrando nessa pesquisa complementa essa perspectiva de Freire et al. (2015), ampliando teoricamente essa dimensão de análise.

A próxima caraterística a ter seus resultados apresentados é postura proativa, entendida como a disposição que deve ter o conselheiro em se antecipar aos fatos que são relevantes às estratégias da empresa e pertinentes às responsabilidades do conselho. Os resultados também demonstram que o conselheiro de administração precisa ter a iniciativa de antever e se manifestar a respeito dos acontecimentos políticos, sociais, econômicos e mercadológicos e que são relevantes às estratégias da empresa. A proatividade se apresenta também, pelo que se pode inferir a partir da análise das falas dos entrevistados, como a capacidade de ouvir, captar informações de interesse e expandir horizontes com opiniões capazes de criar e influenciar novas ideias que agregam valor à empresa e ao desempenho do conselho. Assim como características apresentadas anteriormente, não foram encontrados estudos ao longo da revisão da literatura que corroborassem ou contradissessem os achados.

É importante esclarecer que a tomada de decisão ora pesquisada é aquela concernente à atividade 
de conselheiro de administração de forma individual, resultado da análise realizada sobre determinado projeto, que estará sujeita à decisão do conselho e de sua aprovação por meio de voto. De acordo com os resultados encontrados, a tomada de decisão deve estar baseada na análise dos projetos e documentações sobre sua responsabilidade. Nesse sentido, o conselheiro deve saber se posicionar durante as votações no conselho e defender os interesses da empresa, o que torna a tomada de decisão necessária ao perfil do candidato.

Para os entrevistados, o conselheiro dever ser analisado pelos fundamentos de seu posicionamento, o qual deve ser pertinente, lúcido, coerente e fruto de suas análises, sem ser contaminado pelo excesso de confiança que pode levar ao erro no momento de encaminhar seu voto. Em relação à tomada de decisão, Clark e Maggitti (2012) alertam para excesso de confiança, que ocorre quando o indivíduo faz avaliações subjetivas de resultados positivos alcançados no passado ou quando é estimulado pela opinião de outros membros, o que pode levar a equívocos. Para Clark e Maggitti (2012) as decisões devem ser consequência do estudo crítico e aprofundado, sustentado pela formação acadêmica e experiência profissional. Elbanna, Child e Dayan (2013) adicionam como complemento aos resultados desta pesquisa que diante da instabilidade do ambiente e a urgência de uma decisão, pode ocorrer a tomada de decisão apoiada pelo uso da intuição. Segundo os autores essa estratégia complementa a análise racional em face da incerteza e da falta de informações relevantes.

Por fim, infere-se a partir dos resultados que as características apresentadas nessa seção, apesar de importantes, podem ser aprendidas ou estimuladas pelo presidente do conselho, mas que, em um primeiro momento, não são determinantes à escolha do conselheiro. Obviamente, a falta de tais características pode atrapalhar o desempenho do conselheiro, cabendo ao presidente ações corretivas ou a substituição do conselheiro de administração.

Quando algumas das características consideradas relevantes ao exercício da atividade não são levadas em consideração por quem o está indicando, pode-se culminar no prejuízo do desempenho do conselho e da imagem do próprio conselheiro, em função de suas limitações profissionais ou pessoais.

\section{Considerações Finais}

Esta pesquisa teve por objetivo conhecer as características individuais relevantes ao exercício da atividade de Conselheiro de Administração independente. Os resultados demonstraram que as características individuais sinalizam a existência de interdependência e complementaridade, pois contemplam a formação acadêmica, gênero, idade, alcance de resultados, reconhecimento no mercado, competência da comunicação, conhecimento do ambiente de negócio da empresa, conhecimento da realidade internacional e nacional, habilidade em análise, habilidade para negociar, disposição a cooperar, liderança entre iguais, postura proativa e tomada de decisão.

Essas características, quando encaradas de maneira isolada, deixam de ser determinantes à escolha ou preterimento do candidato à conselheiro de Administração independente. Dessa dedução infere-se que cada característica depende de uma segunda ou terceira que a complemente. Todavia, existem restrições para trajetória e acúmulo de experiências, credibilidade e postura independente. Quanto aos aspectos cognitivos, que dizem respeito ao conhecimento do conselheiro, observou-se sua utilidade para a análise de cenários, geopolítica, balanços, documentos e relatórios de mercado e suas tendências, além da habilidade de negociação focada em conciliação.

A ausência de uma dessas características possibilita preterir o candidato à atividade de Conselheiro de Administração independente, contudo, se possuidor das três e mais nenhuma outra abordada, é possível admitir o candidato, já que essas citadas viabilizam o exercício da atividade.

Conforme observado nos achados deste artigo que endereçaram à resposta da pergunta de pesquisa, destaca-se que as características do conselheiro requisitadas pelos entrevistados transcendem meras indicações baseadas em personalismo, para fundamentos que de fato contribuam para maior profissionalização e atuação deste conselheiro em suas atividades.

As limitações da pesquisa ficam por conta da quantidade de entrevistados e do tempo disponível para análise e tratamento de resultados, visto que o assunto abordado ainda não está esgotado, ensejando comparações internacionais entre processos de escolhas de Conselheiro de Administração. Nova pesquisas podem até complementar ou até corrigir eventuais distorções presentes nos resultados aqui apresentados, enriquecendo as discussões acadêmicas e colaborando com as empresas que têm em sua estrutura 0 Conselho de Administração.

\section{Referências}

AI-MATARI, E.M. Do characteristics of the board of directors and top executives have an effect on corporate performance among the financial sector? Evidence using stock. Corporate Governance, v. 20, n. 1, p. 1643, 2019. https://doi.org/10.1108/CG-11-2018-0358 
AMANN, F. J. O papel do conselho de administração no desenvolvimento de melhores práticas de governança corporativa: o caso Banco do Brasil. Dissertação (Mestrado em Economia). Faculdade de Ciências Econômicas, Universidade Federal do Rio Grande do Sul, Porto Alegre: 2010.

BHAT, K.U., CHEN, Y., JEBRAN, K., MEMON, Z.A. Board diversity and corporate risk: evidence from China". Corporate Governance, v. 20, n. 2, p. 280-293, 2019. https://doi.org/10.1108/CG-01-2019-0001

BARDIN, L. Análise de conteúdo. São Paulo: Edições, 2011

BROWN, W. A. Board development practices and competent board members: Implications for performance. Nonprofit Management and Leadership, v.17, n. 3, p. 301-317, 2007. https://doi.org/10.1002/nml.151

CAMILO, S. P. O.; MARCON, R.; BANDEIRA-DE-MELLO, R. Conexões políticas e desempenho: um estudo das firmas listadas na BM\&FBovespa. Revista de Administração e Contabilidade, v. 16, n. 6, p. 784-805, 2012. https://doi.org/10.1590/S1415-65552012000600003

CHARAN, R. Know-how: as 8 competências que separam os que fazem dos que não fazem. Rio de Janeiro: Elsevier, 2007.

CLAESSENS, S. Corporate governance and development Global. Corporate Conference Forum. Washington: World Bank, 2003. https://doi.org/10.2139/ssrn.642721

CLARK, K. D.; MAGGITTI, P. G. TMT potency and strategic decision-making in high technology firms. Journal of Management Studies, n. 49, v. 7, november, 2012. https://doi.org/10.1111/j.14676486.2012.01060.x

COULSON-THOMAS, C. Competences of an effective director. Industrial and commercial training, v. 41, n. 1, p. 27-35, 2009. https://doi.org/10.1108/00197850910927732

CRESWELL, J. W. Investigação qualitativa e projeto de pesquisa: escolhendo entre cinco abordagens. 3. ed. - Porto Alegre: Penso, 2014.

DARMADI, S. Board members education and firm performance: evidence from a developing economy. International Journal of Commerce and Management, v. 23 n. 2, p. 133-135, 2013.

https://doi.org/10.1108/10569211311324911

DUNN, P. Breaking the boardroom gender barrier: the human capital of female corporate directors. Journal of Management \& Governance, v. 16, n. 4, p. 557-570, 2012. https://doi.org/10.1007/s10997-010-9161-2

EISENHARDT, K. M. Making fast strategic decisions in high-velocity environments. The Academy of Management Journal, v. 32, n. 3, p. 543-576, sep., 1989. https://doi.org/10.5465/256434

ELBANNA, S; CHILD, J.; DAYAN, M. While a model of antecedents and consequences of intuition in strategic decision-making: evidence from Egypt. Long Range Planning, p. 149-176, 2013. https://doi.org/10.1016/j.Irp.2012.09.007

FINKELSTEIN, S.; HAMBRICK, D. C. Top-Management-Team tenure and organizational outcomes: the moderating roie of managerial discretion. Administrative Science Quarterly, n. 35, p. 484-503, 1990. https://doi.org/10.2307/2393314

FREIRE, J. R. S.; CASTRO, A. D. M.; KUBO, E. K. M.; OLIVA, E. C.; SOARES, D. A. S. R. Liderança coletiva: proposta de escala de autoavaliação. Revista de Carreiras e Pessoas, v. 5, n. 01, 2015.

GARBUIO, M.; LOVALLO, D.; SIBONY, O. Evidence doesn't argue for itself: the value of disinterested dialogue in strategic decision-making. Long Range Planning, n. 48, 361-380, 2015.

https://doi.org/10.1016/j.Irp.2015.09.002

GARY, M. S.; WOOD, R. E.; PILLINGER, T. Enhancing mental models, analogical transfer, and performance in strategic decision making. Strategic Management Journal, n. 33, 1229-1246, 2012.

https://doi.org/10.1002/smj.1979 
GOETZ, F. F. Desenvolvimento de modelo do perfil desejado para conselheiros de administração de empresas privadas brasileiras. 2006. Dissertação (Mestrado em Administração) - Escola de Administração, Universidade Federal do Rio Grande do Sul, Porto Alegre, 2006.

HAGUETTE, T. M. F. Metodologias qualitativas na sociologia. 13 ed. Petrópolis, RJ: Vozes, 2011.

HAMBRICK; MASON, P. Upper echelons: The organization as a reflection of its top managers. Academy of Management Review, v. 9, n. 2, p. 193-206, 1984. https://doi.org/10.5465/amr.1984.4277628

IBGC - Instituto Brasileiro de Governança Corporativa. Código das melhores práticas de governança corporativa. 4. ed. São Paulo: IBGC, 2009.

IBGC. Código das melhores práticas de governança corporativa. 5.ed. São Paulo: IBGC, 2015.

KACANSKI, S. Structure behind principles: social selection mechanisms in corporate governance networks. Corporate Governance, v. 20, n.1, pp. 87-105, 2019. https://doi.org/10.1108/CG-02-2019-0063

KACZMAREK, S.; KIMINO, S.; PYE, A. Antecedents of board composition: the role of nomination committees. Corporate Governance: An International Review, v. 20, n. 5, p. 474-489, 2012. https://doi.org/10.1111/j.1467-8683.2012.00913.x

LE BOTERF, G. Professionnaliser: construire des parcours personnalisés de professionnalisation. 7 ed. Paris: Group Eyrolles, 2016.

LIANG, Q.; XU, P.; JIRAPORN, P. Board characteristics and chinese bank performance. Journal of Banking \& Finance, v. 37, n. 8, p. 2953-2968, 2013. https://doi.org/10.1016/j.jbankfin.2013.04.018

MATHISEN, G.; OGAARD, T.; MARNBURG, E. Women in the boardroom: how do female directors of corporate boards perceive boardroom dynamics? Journal Business Ethics, v. 116, n. 1, p. 87-97, 2013. https://doi.org/10.1007/s10551-012-1461-9

MRAD, M.; HALLARA, S. The relationship between the board of directors and the performance/value creation in a context of privatization: the case of french companies. Public Organization Review, v. 14, n. 1, p. 83-108, 2012. https://doi.org/10.1007/s11115-012-0207-6

NADLER. D. A. A construção de um conselho eficaz. Harvard Business Review, p. 1-9, 2004.

OLIVA, E. C.; ODONE, G.; ALBUQUERQUE, L. G. Práticas e Tendências em Governança Corporativa. In: Ademir Lamenza et al. (Coord.) Estratégias empresarias: pesquisas e casos brasileiros. São Paulo : Saint Paul Editora, 2008. p. $33-64$.

OLIVEIRA, D. P. R. Governança corporativa na prática: integrando acionistas, conselho de administração e diretoria executiva na geração de resultados. 2. ed. São Paulo: Atlas, 2011.

OECD - Organization for Economic Co-Operation and Development. Using the OECD principles of corporate governance: a boardroom guide. Organization For Economic Co-Operation and Development, 2004.

OECD. Using the OECD principles of corporate governance: a boardroom guide. Organization For Economic Co-Operation and Development, 2008.

PAPADAKIS, V. M.; BARWISE, P. How much do CEOs and top managers matter in strategic decisionmaking? British Journal of Management, USA, v. 13, p. 83-95, 2002. https://doi.org/10.1111/14678551.00224

PUGLIESE, A.; NICHOLSON, G.; BEZEMER, P-J. An observational analysis of the impact of board dynamics and directors' participation on perceived board effectiveness. British Journal of Management, $v$. 26, n. 1, p. 1-25, 2015. https://doi.org/10.1111/1467-8551.12074

PURDY, J. M.; LAWLESS, J. Learning about governance through nonprofit board service. Journal of Management Education, v. 36, n. 1, p. 33 - 65, 2012. https://doi.org/10.1177/1052562911418196 
RODRIGUEZ, G. M. BRANDÃO, M. M. Visões de governança corporativa: a realidade das sociedades por ações e a sustentabilidade. São Paulo: Saraiva, 2010.

RUAS, R. Desenvolvimento de Competências Gerenciais e Contribuição da Aprendizagem Organizacional. In: DUTRA, J. S.; FLEURY, M. T. L.; RUAS, R. (Coord.). Gestão Estratégica do Conhecimento: integrando aprendizagem, conhecimento e competências. São Paulo: Atlas, 2008, p. 242-269

SANTOS, R. L.; SILVEIRA, A. D. M. Board interlocking no Brasil: a participação de conselheiros em múltiplas companhias e seu efeito sobre o valor das empresas. Revista Brasileira de Finanças, v. 5, n. 2, p. 125-163, 2007. https://doi.org/10.12660/rbfin.v5n2.2007.1173

SILVA, A. B. A Fenomenologia como método de pesquisa em estudos organizacionais. In: GODOI, C. K.; BANDEIRA-DE-MELLO, R.; SILVA, A. B (org.) Pesquisa qualitativa em estudos organizacionais: paradigmas, estratégias e métodos. 2. ed. São Paulo: Saraiva, p. 267-293, 2010.

SILVA, A. L. C.; MAGEM, H. Mulheres em cargos de alta administração afetam o valor e desempenho das empresas brasileiras? Revista Brasileira de Finanças, v. 13, n. 1, p. 102-133, 2015.

https://doi.org/10.12660/rbfin.v13n1.2015.35116

SILVEIRA, A. M.; BARROS, L. A. B. C.; FAMÁ, R. Estrutura de governança e valor das companhias abertas brasileiras. Revista de Administração de Empresas, v. 43, n. 3, p. 50-64, 2003.

https://doi.org/10.1590/S0034-75902003000300005

STEINBERG, H. A dimensão humana da governança corporativa: pessoas criam as melhores e piores práticas. São Paulo: Editora Gente, 2003.

TRIVIÑOS, A. N. S. Introdução à pesquisa em ciências sociais: a pesquisa qualitativa em educação. São Paulo: Atlas, 2015.

VESCO, D. G. D.; BEUREN, I. M. Do the board of directors composition and the board interlocking influence on performance? Brazilian Administration Review, v. 13, n.2, p. 1-16, 2016. https://doi.org/10.1590/18077692 bar2016160007

WAGNER, A F. Board independence and competence. Journal Financial Intermediation, v. 20, n. 1, p. 7193, 2015.

\section{NOTAS}

\section{AGRADECIMENTOS}

Não se aplica.

\section{CONTRIBUIÇÃO DE AUTORIA}

Concepção e elaboração do manuscrito: C. A. Fernandes, E. C. Oliva, E. K. M. Kubo

Coleta de dados: C. A. Fernandes

Análise de dados: C. A. Fernandes, E. C. Oliva, E. K. M. Kubo

Discussão dos resultados: C. A. Fernandes, E. C. Oliva, E. K. M. Kubo

Revisão e aprovação: C. A. Fernandes, E. C. Oliva, E. K. M. Kubo

\section{CONJUNTO DE DADOS DE PESQUISA}

Todo o conjunto de dados que dá suporte aos resultados deste estudo foi publicado no próprio artigo.

\section{FINANCIAMENTO}

Não se aplica.

\section{CONSENTIMENTO DE USO DE IMAGEM}

Não se aplica.

\section{APROVAÇÃO DE COMITÊ DE ÉTICA EM PESQUISA}

Não se aplica.

\section{CONFLITO DE INTERESSES}

Não se aplica. 


\section{LICENÇA DE USO}

Os Direitos Autorais para artigos publicados neste periódico são do autor, com direitos de primeira publicação para a Revista. Em virtude de aparecerem nesta Revista de acesso público, os artigos são de uso gratuito, com atribuições próprias, em aplicações educacionais, de exercício profissional e para gestão pública. A Revista adotou a licença Creative Commons Atribuição 4.0 Internacional - CC BY NC ND. Esta licença permite acessar, baixar (download), copiar, imprimir, compartilhar, reutilizar e distribuir os artigos desde que com a citação da fonte, atribuindo os devidos créditos de autoria. Nesses casos, nenhuma permissão é necessária por parte dos autores ou dos editores. Autores têm autorização para assumir contratos adicionais separadamente, para distribuição não-exclusiva da versão do trabalho publicada nesta revista (ex.: publicar em repositório institucional ou um capítulo de livro).

\section{PUBLISHER}

Universidade Federal de Santa Catarina. Curso de Ciências Contábeis e Programa de Pós-graduação em Contabilidade. Publicação no Portal de Periódicos UFSC. As ideias expressadas neste artigo são de responsabilidade de seus autores, não representando, necessariamente, a opinião dos editores ou da universidade.

\section{EDITORES}

Carlos Eduardo Facin Lavarda e Suliani Rover

\section{HISTÓRICO}

Recebido em: 06/03/2019 - Revisado por pares em: 27/04/2020 - Reformulado em: 03/06/2020 Recomendado para publicação em: 05/06/2020 - Publicado em: 30/06/2020 